\title{
IDENTIFICAÇÃO E EXPLORAÇÃO DE OPORTUNIDADES INTERNACIONAIS: Estudo de Caso no Setor de Economia Criativa
}

Vitor Pires Dos Santos ${ }^{1}$

Daniel Kamlot ${ }^{2}$

\footnotetext{
${ }^{1}$ COPPEAD / Universidade Federal do Rio de Janeiro

${ }^{2}$ Escola Superior de Propaganda e Marketing/ESPM-Rio
} 


\section{IDENTIFICAÇÃO E EXPLORAÇÃO DE OPORTUNIDADES INTERNACIONAIS: Estudo de Caso no Setor de Economia Criativa}

Resumo: O presente estudo tem como objetivo analisar os tipos de oportunidades e o processo identificação e exploração de oportunidades internacionais de uma empresa brasileira atuante na indústria de economia criativa - a Franco Produções e Filmes - na implementação da sua estratégia empresarial de internacionalização. A metodologia utilizada foi a pesquisa qualitativa, com a utilização de estudo de caso único, e o levantamento das informações foi realizado por meio de entrevistas em profundidade e de pesquisa documental. Os resultados obtidos permitem observar que as dimensões networks, flexibilidade de recursos, conhecimento, perfil do empreendedor e adaptação ao ambiente, analisados no caso Franco Produções e Filmes, foram fundamentais no processo identificar e explorar oportunidades internacionais, bem como maximizar a criação e a entrega de valor de suas produções culturais.

Palavras-chave: Oportunidades internacionais. Exploração de oportunidades. Internacionalização. Empreendedorismo internacional

\section{Introdução}

O setor de economia criativa vem ganhando destaque nos estudos e pesquisas, como campo de atuação econômico e social, pela capacidade de gerar crescimento e desenvolvimento econômico, geração de emprego e renda, inclusão social, diversificação cultural, desenvolvimento do capital humano, interação dos aspectos econômicos, culturais e sociais com tecnologia e a geração de propriedade intelectual (UNCTAD,2010).

Segundo os dados da Federação das Indústrias do Estado do Rio de Janeiro (FIRJAN) as indústrias do setor de economia criativa geraram uma riqueza de $\mathrm{R} \$ 155,6$ bilhões para a economia brasileira em 2015. Na ótica da produção, o setor se mostrou menos impactado ante o cenário econômico adverso do período 2013-2015, quando comparada à totalidade da economia nacional: a participação do PIB Criativo estimado no PIB Brasileiro cresceu de 2,56\% para 2,64\%. Em 2015, o setor contemplava aproximadamente 239 mil empresas e empregava 851,2 mil profissionais formais. Números que reforçam cada vez mais o papel estratégico da economia criativa na atividade produtiva brasileira (MAPEAMENTO DE ECONOMIA CRIATIVA DA FIRJAN, 2016).

A economia criativa é uma área de estudos relativamente recente, com estudos inicializados a partir da década de 1990 na Austrália e posteriormente desenvolvida na Inglaterra (BLYTHE, 2001). Alguns autores desenvolvem pesquisas sobre aspectos específicos da economia criativa, como Scott (1997) com o conceito da economia das Cidades Criativas, Florida (2002, 2003) que apresenta a importância das Classes Criativas e Wyszomirski (2004) com uma definição ilustrada do mapeamento do setor criativo. Para White, Gunasekaran e Roy (2014) a Indústria Criativa tem se tornado uma das mais importantes forças de vantagem competitiva na economia das nações.

As primeiras pesquisas sobre internacionalização de empresas tinham um foco na análise da experiência interna da empresa e do aprendizado gradual sobre mercados e operações internacionais. Mas foram sendo substituídas, principalmente nas últimas décadas, por estudos
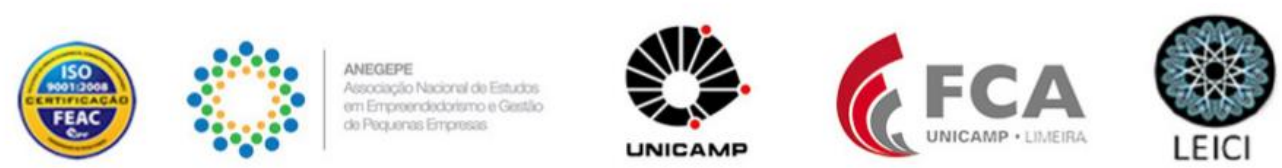
mais aprofundados sobre empreendedorismo internacional, onde se destaca o estudo da identificação e exploração das oportunidades internacionais. (MAINELA, PUHAKKA E SERVAIS, 2013).

A internacionalização pode ser vista como o processo de identificação, desenvolvimento e exploração de oportunidades além de fronteiras nacionais. (SHANE; VENKATARAMAN, 2000). É a partir dessas oportunidades que as empresas conseguem servir novos mercados e clientes de forma lucrativa.

Neste trabalho, é examinado o caso de uma empresa brasileira produtora de cinema, peças teatrais, eventos e projetos culturais, sediada no Rio de Janeiro, enquadrada no segmento cultural e de mídias da indústria criativa, setor que tem apresentando valores substanciais no comércio exterior brasileiro. De 2014 para 2015, as exportações de serviços de audiovisual subiram $110 \%$, alcançando R \$ 154,8 milhões. No mesmo ano, as exportações de serviços como um todo caíram 9\%, para $\mathrm{R} \$ 18,9$ bilhões. (INOVA, 2017)

Neste contexto, o presente artigo pretende analisar o processo de identificação e exploração de oportunidades internacionais de uma produtora brasileira independente do setor audiovisual na implementação da sua estratégia de internacionalização. Buscou-se analisar os tipos de oportunidades reconhecidas pelo empreendedor, bem como identificar os fatores que levaram a sua exploração.

A pesquisa visa contribuir com um tema ainda pouco discutido e que aos poucos vem ganhando importância e interesse de centros de pesquisas em universidades, conferências e publicações. São exemplos da emergência da economia criativa na academia brasileira os estudos de Dalla Costa e Souza - Santos (2011), Bendassolli et. al. (2008), o mapeamento da indústria criativa no Brasil da FIRJAN (2016), os relatórios do IPEA (2013). Instituições como a APEX (Agência Brasileira de Promoção de Exportações e Investimentos) e Fecomércio também são responsáveis pela promoção de debates sobre o assunto.

O artigo foi organizado em seis seções, como segue: além desta introdução, constrói-se o referencial teórico na seção 2, onde se discorre sobre a teoria que aborda os conceitos de oportunidade, oportunidade internacional, identificação e exploração de oportunidades internacionais; na seção 3, descreve-se a metodologia de pesquisa utilizada; na seção 4 expõese o caso da empresa e a sua análise à luz do referencial teórico; e, por fim, na seção 5 são feitas as considerações finais e na seção 6 , são apresentadas as referências utilizadas no estudo.

\section{Referencial Teórico}

\subsection{Conceitos de Oportunidade e Oportunidade Internacional}

De acordo com Schumpeter (1942), oportunidades são novas combinações de recursos. Essas novas combinações podem gerar não só novos produtos ou serviços, mas também novas matérias primas, novos mercados ou até mesmo, novos métodos de produção. Kirzner (1979), por outro lado, define oportunidade como imperfeições de mercados. Essas imperfeições são como lacunas, que devem ser aproveitadas para que a empresa produza novos serviços, produtos ou entre em novos mercados.

Outra definição é a de Oliveira (1989) que conceitua oportunidade como forças ou eventos que acontecem no meio em que a empresa se encontra, mas que fogem de seu controle. Caso essas oportunidades sejam conhecidas e aproveitadas enquanto existirem, podem guiar a empresa na realização de ações estratégicas.

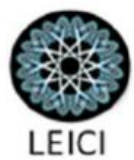


Nesse estudo, seguiremos a definição de Stevenson e Jarillo (1896), no qual oportunidade seriam as circunstâncias positivas e favoráveis que direcionam a organização para uma determinada ação. Assim, a empresa pode atingir um estado futuro desejável que é diferente do estado atual.

De acordo com Ellis (2011), oportunidade internacional, significa a chance de realizar uma "troca", com stakeholders internacionais. São novos parceiros, em novos mercados, aonde um player seria o vendedor e o outro player seria o comprador. Na perspectiva do vendedor, é a viabilidade de novos demandantes e na perspectiva do comprador, novos ofertantes. Após essa troca, todos saem ganhando. Esses novos parceiros podem ser intermediários (atacadistas, varejistas) ou novos clientes finais.

A oportunidade internacional pode ser ainda definida como a oportunidade de criar valor nas empresas através da combinação de comportamentos inovadores, proativos e arriscados, que atravessam as fronteiras nacionais. (CASULLI, 2009).

No processo de internacionalização é essencial que a empresa identifique e explore as oportunidades internacionais. Considera-se esse trabalho mais complexo quando comparado com as oportunidades nacionais, já que as oportunidades internacionais são altamente influenciadas por aspectos culturais, políticos e econômicos do país de origem, fugindo, muitas vezes, da influência e do conhecimento da própria empresa.

No que se refere à categorização das oportunidades, Mainela, Puhakka e Servais (2013), classificam as oportunidades de acordo com a atividade econômica desempenhada pela oportunidade e também pelo comportamento empreendedor pela qual aquela oportunidade é tratada. Com relação à atividade econômica as oportunidades são divididas entre oportunidade inovadora e oportunidade arbitrária. Já em relação ao comportamento empreendedor, elas são classificadas entre oportunidade descoberta e oportunidade criada.

Oportunidades inovadoras movimentam o mercado do estado de equilíbrio em direção ao desequilíbrio na medida em que promovem uma destruição criativa, levando ao mercado novas soluções e de maior valor agregado se compararmos com as soluções que haviam previamente (SCHUMPETER, 1934). Essa oportunidade surge a partir da insatisfação dos empreendedores com o cenário atual em que se encontram. E os fatores que direcionam o desenvolvimento dessas oportunidades são a criatividade, motivação, propensão ao risco e atitude (MCMULLEN; SHEPHERD,2006). Na oportunidade inovadora, a demanda ou a oferta para este novo negócio não estão presentes ainda, dessa forma é necessário que haja uma avaliação e estruturação econômica antes que o novo negócio seja criado. (ECKHARDT; SHANE 2003).

Já a oportunidade arbitrária, surge nos mercados em estado de desequilíbrio, na medida em que o empreendedor identifica uma disparidade entre a oferta e a demanda e então move o mercado de volta para o equilíbrio (ANOKHIN; WINCENT; AUTIO, 2011). Oportunidades arbitrárias surgem de falhas no mercado que resultam em ineficiências (MAINELA; PUHAKKA; SERVAIS, 2013). Os empreendedores conseguem identificar essas ineficiências a partir de suas habilidades para adquirir, interpretar e usar diferentes fontes de informação (ECKHARDT; SHANE, 2003). A oportunidade arbitrária não cria um novo valor econômico ou novos negócios no mercado, mas permite que empresas ou empreendedores operem sobre desejos que não estavam sendo satisfeitos pelo mercado. (MAINELA, PUHAKKA E SERVAIS, 2013).

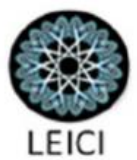




\subsection{Descoberta e Criação de Oportunidades}

No processo de internacionalização as oportunidades precisam ser identificadas, podendo ser descobertas ou de alguma forma, criadas. Enquanto algumas empresas alocam tempo e esforço para descobrir oportunidades, outras empresas preferem usar seus recursos criando oportunidades e sendo, portanto pioneiras em determinada situação.

Kirzner e Schumpeter dividem as discussões acerca de como essas oportunidades são originadas. Enquanto Kirzner afirma que as oportunidades estão no ambiente esperando para serem descobertas, Schumpeter diz que as oportunidades são criadas através de destruições criativas (AKERMAN, 2015).

As oportunidades descobertas, também chamadas de oportunidades Kirzenerianas são aquelas que levam o mercado do desequilíbrio ao equilíbrio, são menos inovadoras e limitadas à descoberta (FAROQUE, 2014). Nessa corrente teórica, afirma-se que as oportunidades surgem por fatores exógenos às organizações, sejam eles, preferências dos clientes, novas tecnologias ou qualquer outro atributo que foge do controle da empresa (KIRZNER, 1973). Outros fatores como aspectos políticos e legais, questões sociais e demográficas também podem gerar novas fontes oportunidades (SHANE, 2003). Essas oportunidades existem originalmente no ambiente, independente das empresas, e estão esperando para serem descobertas e exploradas. As empresas precisam, portanto, somente se preocupar em pesquisar e localizar essas imperfeições de mercado (LEVINTHAL, 1997).

No processo de criação, as oportunidades são originadas endogenamente, pelas ações e reações de empreendedores ou empresas, que buscam novas formas de produzir serviços ou produtos (WEICK, 1979).

O processo de criação de uma oportunidade tem origem em uma ação que acontece sem total consciência, planejamento ou previsão, ocorrendo a partir de pensamentos e hipóteses criativas (ALVAREZ E BARNEY, 2007). Ao contrário da exploração de oportunidades que tem uma abordagem mais retrospectiva no tratamento de dados, na criação de oportunidades, a criatividade é o fator determinante na criação e tratamento das hipóteses acerca da oportunidade em questão (MILLER, 2007).

A partir da criação da oportunidade, inicia-se uma cadeia de ação e reação que termina com a construção e consequente exploração da oportunidade, ou seja, é um processo de causa e efeito (ALDRICH; KENWORTHY, 1999). Diferentemente da descoberta de oportunidades, na qual a empresa seleciona o ambiente de trabalho, na criação de oportunidades, o ambiente não é selecionado, mas sim construído. (ALVAREZ E BARNEY, 2007).

Hoje, no entanto é comum os estudiosos afirmarem que ambos os tipos de oportunidade podem acontecer num mesmo momento em um mesmo lugar (SHANE; VENKATARAMAN, 2000).

Em um estudo feito por Ardichvili, Cardozo e Ray (2003), os autores apresentaram os seguintes fatores como constitutivos do processo de identificação de oportunidades internacionais: alerta empreendedor, informação assimétrica e conhecimento prévio, descoberta versus a busca sistemática, exploração de networks e o perfil empreendedor.

\subsection{Exploração de Oportunidades Internacionais}

A exploração de oportunidades refere-se às ações para efetivar a oportunidade em resultados reais, transformando oportunidades internacionais em atividade econômica

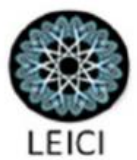


(SODERQVIST, 2011). Nesta etapa busca-se entender e definir como o produto ou serviço será oferecido ao mercado, quem serão os consumidores, quais recursos serão necessários e até mesmo como a cadeia de suprimentos e as operações devem ser estruturadas. (ARDICHVILLI; CARDOZO; RAY, 2003).

Com a exploração de oportunidades internacionais as empresas conseguem melhorar sua posição competitiva em novos países, criando valor para novos clientes e satisfazendo-os, fortalecendo ainda seu poder de barganha em cima de fornecedores e clientes, além de conseguir mais vendas e lucros (FAROQUE, 2014).

De acordo com Zahra (2005), na exploração de oportunidades internacionais a empresa precisa ter criatividade e inovar não só para identificar a oportunidade, mas também para alocar os recursos de forma correta e selecionar a área de internacionalização. $\mathrm{O}$ autor cita ainda que na exploração de oportunidades internacionais a empresa enfrenta um maior nível de risco, em relação ao ambiente nacional. Isso decorre principalmente por se tratar de um mercado em que a empresa tem menor influência, menor conhecimento e em muitas vezes, quase ou nenhuma experiência.

A exploração de oportunidade, inclui atividades como, avaliação, mobilização de recursos, implementação e comercialização da oportunidade. (SODERQVIST, 2011)

$\mathrm{Na}$ avaliação da uma oportunidade, as empresas determinam se vale a pena aproveitar a oportunidade de acordo com aspectos como retorno, custo, demanda do mercado e ciclo de vida da oportunidade. A exploração de uma oportunidade requer que o empreendedor acredite que o valor esperado do lucro será suficiente para compensar o custo com a oportunidade, bem como a falta de liquidez do investimento, de tempo e de dinheiro (SHANE; VENKATARAMAN, 2000).

Após avaliação e decisão de prosseguir no processo de exploração da oportunidade a empresa precisa identificar e alocar os recursos necessários. É nesse momento, de mobilização de recursos, que a empresa avalia os requisitos para tal exploração de oportunidades, identificando os recursos não só financeiros e materiais como também os recursos humanos e de conhecimento necessários. Após essa etapa, parte-se para a implantação, com a coordenação dos esforços para a realização do projeto.

Alguns estudos (ELLIS, 2011; ARDICHVILI; CARDOZO; RAY, 2003) citam fatores que podem auxiliar o processo de exploração de oportunidades internacionais, são eles: networks, flexibilidade de recursos, conhecimento e aprendizado, pressões do ambiente externo e perfil do empreendedor.

\section{Networks}

Empresas que já possuem conhecimento sobre o mercado internacional ou algum tipo de relação internacional conseguem explorar oportunidades internacionais de forma mais estruturada, integrando seus recursos e capacidades nos novos mercados de forma organizada e sistemática. Isso comprova que um maior conhecimento sobre o mercado internacional, ajuda a diminuir o risco de um processo de internacionalização. Já que a empresa consegue explorar a oportunidade de forma mais consciente e, portanto, com mais segurança (CHANDRA; STYLES; WILKSON, 2009; SAARENKETO et al. 2004).

O network da empresa e o seu relacionamento com stakeholders internacionais pode promover uma vantagem no processo de internacionalização já que a empresa tem acesso à informações e recursos internacionais, dos quais não teria acesso sem esses contatos (ELLIS,
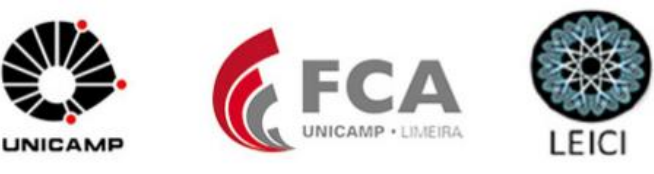
2011). Uma forma propícia para a criação de networks para a internacionalização é através de participação de feiras e workshops (OZGEN; BARON 2007). Os eventos podem propiciar fontes de informações e desenvolvimento de relacionamentos com potencial para impulsionar a identificação de oportunidades internacionais (KONTINEN; OJALA, 2011).

\section{Flexibilidade de recursos}

De acordo com Judge e Blocker (2008) e Danneels (2003), outro aspecto importante para auxiliar na exploração de oportunidades, é a capacidade da empresa de ser flexível e se adaptar ao mercado. Desta forma a empresa consegue seguir as dinâmicas do ambiente nacional e/ou internacional - além de capturar oportunidades localizadas na periferia do mercado, ou seja, oportunidades mais distantes da realidade da empresa - mas que podem trazer grandes retornos.

A flexibilidade de recursos é uma capacidade adaptativa da empresa que á permite reconhecer oportunidades lucrativas e se adaptar aos desejos do ambiente internacional e ainda aproveitar essas oportunidades no intuito de ter uma experiência de internacionalização com maiores retornos (FAROQUE, 2014).

\section{Conhecimento e aprendizado}

A capacidade para explorar oportunidades internacionais, está intimamente ligado à competência do rápido aprendizado e da capacidade de acumular conhecimento. (AUTIO, SAPIENZA, ALMEIDA, 2000). O conhecimento prévio que se origina da experiência no trabalho, da educação ou de outras fontes influencia a capacidade do empreendedor para entender, extrapolar, interpretar e aplicar novas informações de uma forma que os outros não conseguem (SHANE, 2000).

No entanto, conforme argumentado Corbett (2007), para explorar oportunidades internacionais, não baste somente ter conhecimento prévio, mas principalmente a capacidade de explorar e usar esse conhecimento.

\section{Pressões do ambiente externo}

Compreender o ambiente é importante para explorar a oportunidade no momento oportuno. Uma forma usual e importante de se ter acesso a oportunidades ou avalia-las é a verificação de tendências ambientais. Em geral, estas tendências, que podem ser globais ou regionais, envolvem aspectos sociais políticos, econômicos tecnológicos e demográficos. As tendências, e assim, as oportunidades, mudam com o tempo e com o contexto. Sendo por isto necessário que os empreendedores e, mesmo negócios tradicionais, de tempos em tempos estejam avaliando como modificam as tendências para avaliar a continuidade de seus negócios (FERREIRA, M.P.; REIS, N.; SERRA, F.R., 2014).

As empresas e os empreendedores podem enfrentar uma série de obstáculos no processo de identificação e exploração de oportunidades. Os três principais são: organizacionais, ambientais e relacionados ao pessoal. Estes obstáculos variam de acordo com o tipo de empresa, seu ambiente, seu negócio e até com o ciclo de vida de seus produtos e sua história no mercado (DE BONO, 1989).

\section{Perfil do Empreendedor}

O empreendedor é aquele que vê a mudança como normal e como sendo sadia. Em geral, esses indivíduos não provocam a mudança por si mesmos, mas estão sempre buscando-a, reagindo a ela e explorando-a como sendo uma oportunidade (DRUCKER, 1986). Welpe et al

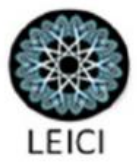


(2012) citam coragem, iniciativa, otimismo e criatividade como traços de personalidade que podem de certa maneira, facilitar o processo de identificação de oportunidades.

\section{Metodologia da Pesquisa}

Para este trabalho, de caráter exploratório, optou-se pela metodologia qualitativa, por meio de estudo de caso único. O presente trabalho de pesquisa seguiu as três etapas definidas por Dellagnelo e Silva (2005) e baseadas em Bardin (1994): em primeiro lugar, foi realizada uma pré-análise, que corresponde à preparação do processo, onde foram definidos os entrevistados, realizada as entrevistas e as transcrições das mesmas, além da organização da estrutura do trabalho. No segundo momento, foi analisado o material, com categorização dos temas a serem abordados no processo da verificação, entendendo-se estas categorias como elementos ou aspectos com características comuns ou que se relacionavam entre si. E, por fim, procedeu-se a interpretação, entendida como o momento da ponderação, da intuição com embasamento no corpus e no referencial teórico selecionado, buscando estabelecer relações, verificar contradições e compreender o fenômeno.

A coleta de dados iniciou-se por meio de informações disponibilizadas pela própria empresa, em seu website (http://francoprod.com.br), bem como artigos de revistas e jornais, casos de ensino sobre ela e seus produtos. No segundo momento, foi realizada uma entrevista, no período compreendido entre novembro e dezembro de 2016, com o fundador e principal gestor, Ailton Franco Júnior, responsável pelas estratégias de negócio e internacionalização da empresa. Com um total de 2 horas, a entrevista foi gravada e transcrita integralmente para melhor análise dos materiais coletados. Para a coleta de dados, foi utilizado um roteiro de entrevista semiestruturado que buscou informações sobre a empresa, o contexto, sua história e seu processo de internacionalização. As diferentes fontes de dados permitiram uma visão sistêmica e uma triangulação de informações, validando a metodologia e auxiliando o processo analítico do trabalho.

A escolha de um estudo de caso único deu-se por ser um caso crítico e peculiar (YIN, 2005). Pelo aspecto crítico, destaca-se a sua importância no reforço e aplicabilidade da teoria do empreendedorismo internacional em pequenas empresas brasileiras. No quesito peculiaridade, a empresa analisada apresenta relevância por abordar o setor de economia criativa, mais precisamente de Audiovisual, área que tem atraído muito o interesse da academia no que diz respeito às experiências de internacionalização.

\section{Apresentação e Análise do Caso \\ Perfil da empresa}

A Franco Produções e Filmes é uma produtora de cinema, teatro, eventos e projetos culturais. É gerenciada por Ailton Franco Junior, formado em Cinema e Economia pela UFF, diretor-presidente e produtor na empresa, profissional com mais de 24 anos de experiência nessa indústria. Possui experiência internacional, desenvolvida não só por meio de viagens particulares, mas também pela atuação profissional. Já participou de diversos eventos no exterior, como os festivais de Cannes na França e o Ventana Sur, na Argentina.

Ailton Franco mantém uma relação próxima com a França, além do francês fluente, já fez cursos sobre produção cultural no país e em 2016, desenvolveu uma coprodução cinematográfica com uma empresa daquele país. Em sua carreira, já produziu filmes, documentários, material para televisão, eventos nacionais e internacionais, além de atuar também como consultor internacional na área audiovisual.
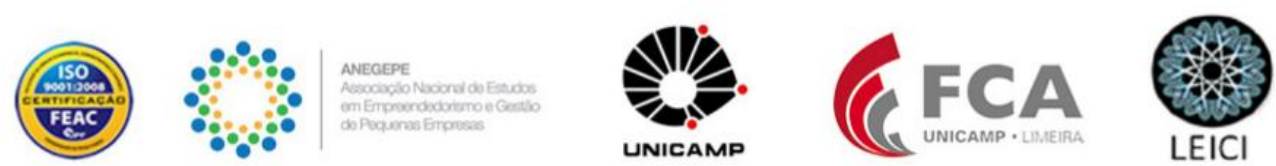
A história da empresa tem início na década de 90, mas precisamente em 1991, no período do governo do presidente Fernando Collor, época que o país passava por sérios problemas políticos e econômicos, que geravam reflexos negativos no contexto da produção cultural. Nesse período, Ailton Franco estava terminando o curso de cinema identificou uma oportunidade de criar um festival de curtas metragens para aplicar seus conhecimentos. No ano seguinte, em 1992, decidiu que era o momento de criar uma produtora cultural para continuar produzindo o festival e tendo um amigo de faculdade como sócio, criou a AR Empreendimentos.

Em 2007, a sociedade foi desfeita, Ailton Franco passou a ser o único proprietário da empresa, que passou a se chamar Franco Produções e Filmes. Hoje a empresa possui prêmios em diversas categorias, com destaque para o Festival Internacional de Curtas do Rio de Janeiro, evento a cargo da Associação Franco Cultural, outra organização do grupo. A empresa já produziu longas e curtas metragens, documentários, material para a televisão, mostras de cinema e festivais. Além da atuação na área audiovisual, a empresa produz espetáculos teatrais, de dança, montagem de ópera, organização de turnês nacionais e internacionais, montagem de exposições e formatação de projetos culturais com outras empresas ou criadores.

Em 2010, lançou seu primeiro filme de longa metragem "Agreste", em 2013, lançou seu segundo filme, intitulado "Exilados do Vulcão". Atualmente, está desenvolvendo um novo projeto de longa-metragem, o filme Rivermovie. Ailton Franco já produziu mais de 10 curtas, entre produções próprias e em coprodução com outras produtoras. As produções são distribuídas e difundidas no Brasil e no exterior.

Além da Franco Produções e Filmes, Ailton Franco também preside a Associação Franco Cultural. Fundada em 2001, com o objetivo de realizar projetos culturais e educacionais.

Em 2006, a Franco Produções e Filmes iniciou seu processo de internacionalização, através da produção da turnê da peça teatral Ensaio. Hamlet, exibida no Under the Radar Festival, Public Theater, em Nova York, Estados Unidos. O Festival Under The Radar é um programa desenvolvido pela Associação dos Apresentadores das Artes Performáticas para sua conferência anual e conta com o expressivo apoio financeiro das Fundações Andrew W. Mellon e Ford. O Festival é produzido por Mark Russell e The Public Theater. Essa mesma peça, do diretor Enrique Diaz, também foi levada para a França pela equipe da Franco Produções e Filmes.

Em termos de coprodução de filmes, desenvolveu dois projetos internacionais. O primeiro projeto de coprodução foi com uma empresa da Argentina, que fracassou por conta de problemas de calendário do filme e da falta de recursos financeiros. Ailton Franco desfez a parceria e o filme acabou sendo realizado apenas pelo produtor argentino. O segundo projeto aconteceu em 2015, uma coprodução com uma produtora francesa, Daigoro Films, que resultou no filme "Kali", dirigido pelo francês Julien Seri. Para esse filme, a Franco Produções e Filmes foi a proponente minoritária do projeto com $25 \%$ de participação, enquanto a produtora francesa deteve $75 \%$ de participação.

Nos últimos três anos, a Franco vem desenvolvendo projetos de coprodução internacional de filmes. São projetos no qual empresas de países diferentes, se unem através de uma parceria para desenvolver um filme em conjunto, aproveitando os recursos e capacidades de cada empresa.

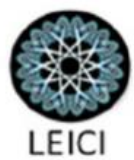


No que se refere aos principais benefícios alcançados pela Franco Produções e Filmes com a internacionalização, na visão de seu gestor, foram: o estabelecimento de novos relacionamentos para projetos futuros, desenvolvimento de novas redes de relacionamento, aumento do faturamento e dos lucros e a possibilidade de aprendizado de novos conhecimentos. Análise do caso Franco Produções e Filmes à Luz do Processo de Identificação e Exploração de Oportunidades Internacionais

O processo de identificação e exploração de oportunidades internacionais apresenta algumas características. Essas características serão utilizadas para ilustrar como a empresa conseguiu identificar oportunidades de internacionalização e como essas oportunidades foram exploradas. Para a análise do caso vamos considerar os dois tipos de projetos internacionais implementados pela empresa até o momento, a produção de turnês internacionais de teatro e coprodução de filmes.

Com relação à classificação do tipo de oportunidade na internacionalização da Franco Produções e Filmes, a oportunidade de realização da turnê internacional pode ser classificada como uma oportunidade arbitrária, enquanto a coprodução pode ser considerada uma oportunidade inovadora.

Segundo Mainela, Puhakka e Servais (2013), oportunidades arbitrárias surgem de falhas no mercado que resultam em ineficiências. Os empreendedores conseguem identificar essas ineficiências a partir de suas habilidades para adquirir, interpretar e usar diferentes fontes de informação (ECKHARDT; SHANE 2003). No caso da turnê, já havia uma demanda - uma empresa contratante - e a oferta, representada pelo serviço da empresa brasileira. Não houve a criação inédito ou inovador. Verifica-se que a demanda e a oferta já estavam presentes, cabendo ao empreendedor apenas reconhecer e explorar a oportunidade, equilibrando oferta e demanda. (ECKHARDT; SHANE 2003).

No que diz respeito à coprodução internacional, esse tipo de projeto, inicialmente, pode não ter demanda. Na oportunidade inovadora, a demanda ou a oferta para um novo negócio podem não existir, dessa forma faz-se necessário efetuar uma avaliação e estruturação econômica antes de criar o novo negócio (ECKHARDT; SHANE 2003). No setor audiovisual, é a partir da criatividade, motivação e atitude que os filmes são criados e os parceiros estabelecidos. Esses produtos culturais apresentam uma nova proposta ao mercado e criam valor econômico. Durante a entrevista, Ailton Franco falou sobre isso:

"No caso do teatro foi muito específico, já havia essa demanda, era uma peça que já estava na programação, já estava estabelecido. Então foi uma demanda deles que já existia. No caso de coprodução internacional de filmes, o resultado do filme é uma incógnita você pode ter um filme com um bom público ou não ter. E sim, é uma demanda que não tínhamos, nós criamos."

Além disso, constatou-se que a oportunidade arbitrária, foi efetivamente descoberta enquanto a oportunidade inovadora foi criada.

No primeiro caso, a oportunidade de fazer a turnê poderia ter sido aproveitada por outra empresa, algum concorrente, pois essa oportunidade era real e já estava disponível no mercado para os produtores interessados. A Franco Produções e Filmes, no entanto, foi escolhida como a prestadora do serviço, por uma preferência da empresa contratante, fazendo com que a oportunidade fosse descoberta a partir de uma demanda do mercado. Esse contexto ratifica os pressupostos de Mainela, Puhakka e Servais (2013) de que uma oportunidade arbitrária não cria

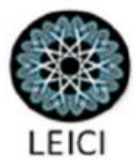


um novo valor econômico ou novos negócios no mercado, mas permite que empresas ou empreendedores operem sobre desejos que não estavam sendo satisfeitos pelo mercado.

Já no segundo caso, a coprodução foi uma oportunidade criada, tendo em vista, que a mesma surgiu da ideia de criar um novo filme, um novo produto que antes não existiam e que foram criadas. O que corrobora com Kirzner (1973) que afirma que apesar das oportunidades estarem disponíveis no ambiente, o motivo pelo qual somente algumas empresas conseguem identifica-las se dá pelo alto nível de alerta empreendedor e aceitação ao risco.

O seguinte comentário de Ailton Franco confirma essa análise:

"No caso da Turnê, era uma oportunidade que já estava disponível, eles contrataram a gente, mas por algum motivo outra empresa poderia ter sido contratada no nosso lugar. Mas na coprodução não, a gente que criou o projeto todo, a partir do nosso esforço e da criatividade."

Outro ponto que corrobora se a oportunidade foi descoberta ou criada é com relação à consciência do empreendedor sobre as consequências esperadas do projeto. Na oportunidade das turnês, Ailton Franco já possuía expectativas em termos de resultados esperados, o que caracteriza uma oportunidade descoberta. Para Alvarez e Barney (2007) no processo de descoberta de oportunidades, o empreendedor adquiri informações variadas, antes de explorar ou aproveitar a oportunidade. O mesmo não ocorreu com a coprodução do longa metragem, na qual Ailton Franco não possuía muitas informações e previsões sobre os resultados que poderiam ser atingidos. Nesse caso, a consequência é mais incerta, representando uma oportunidade criada. Ailton Franco trata sobre esse assunto da seguinte forma:

Na turnê a gente sabia o que esperar, que era o nosso pagamento. Na coprodução, a gente tem uma ideia do que a gente espera alcançar em termos de engajamento do público, mas como eu falei antes, é uma incógnita, o filme pode ter ou não uma boa repercussão. Acho que para os filmes, a consequência é mais incerta."

A partir do exemplo da Franco Produções e Filmes, pode-se perceber que uma mesma empresa pode identificar diferentes tipos de oportunidade, em diferentes momentos (SHANE; VENKATARAMAN, 2000).

De acordo com Franco, o trabalho da produção cultural é materializar o que foi escrito no roteiro, no script daquele projeto. Dessa forma, a exploração da oportunidade internacional, nesse caso, foi o ato de tornar real, aquilo que estava no papel. Criar e oferecer o espetáculo ou filme num mercado estrangeiro.

"Tem que pensar em todos os detalhes, desde a viagem, visto, enviar alguma coisa pelo correio, seguros, hospedagem. E quando começa a produzir o espetáculo ou o filme, tem que planejar tudo que você vai fazer, o que vai precisar comprar, contratar, organizar as pessoas..."

No processo de exploração de oportunidades, mais precisamente na etapa de avaliação da oportunidade, percebe-se que no caso da turnê teatral nos Estados Unidos, não havia uma preocupação com o risco do retorno financeiro, visto que independentemente do resultado, a empresa receberia o pagamento estabelecido no contrato. A avaliação ocorreu pela comparação da remuneração dos serviços com os custos do projeto. Na coprodução, por outro lado, existiu uma preocupação maior com o resultado financeiro do projeto, porém, não foi realizada nenhuma avaliação financeira da oportunidade. Ailton Franco citou:

“Não teve uma avaliação financeira formal. A gente tem mais noção do resultado quando já tem o projeto finalizado e começa a distribuir. No caso da turnê de teatros, a perspectiva de retorno não era pra mim essencial, a gente estava lá mais

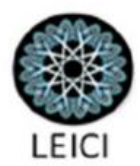


como uma empresa contratada. Era um trabalho mais pontual e que eu receberia uma remuneração. Isso é bem diferente do caso de uma coprodução, em que eu preciso de retorno do investimento."

A partir dessa situação, verifica-se que, quanto maior o engajamento da empresa no projeto cultural internacional, maior a sua percepção de risco e, portanto, maior a necessidade de uma avaliação financeira do negócio (SHANE; VENKATARAMAN, 2000).

Uma consideração a ser feita é que a empresa anteriormente já havia feito uma tentativa fracassada de coprodução com a uma empresa da Argentina, mas por questões financeiras o projeto teve que ser interrompido. Caso tivesse sido realizada uma avaliação financeira prévia, esse problema poderia ter sido evitado. Isso reforça a importância das empresas realizarem uma avaliação financeira prévia das oportunidades, antes de efetivamente começar sua exploração.

Sobre a flexibilidade de recursos para explorar as oportunidades internacionais, Franco comenta:

\section{"No meu caso, na produção de teatros e filmes, naturalmente, sempre surgem necessidades locais, no país da produção. E você tem que procurar alternativas para satisfazer essas necessidades."}

Isso confirma que os projetos internacionais, a complexidade para organizar e mobilizar recursos é bem maior quando comparado com os projetos nacionais. Inclusive, pelo tipo de negócio e operação de uma empresa de audiovisual, que geralmente, precisa contratar funcionários temporários nos países em que está atuando. Essa atividade pode representar um fator crítico para o sucesso de suas produções internacionais.

No setor de produção cultural e demais setores da economia criativa destaca-se a importância e das networks dos empreendedores no processo de internacionalização. No caso da Franco Produções e Filmes, as redes de relacionamento representaram um aspecto decisivo na realização dos projetos internacionais, influenciando de forma determinante a escolha do mercado a ser abordado na internacionalização. Com relação à coprodução realizada entre a empresa brasileira Franco e uma produtora francesa, Ailton comentou:

"No caso dessa coprodução com a França, eu já conhecia o Julien Seri diretor e produtor francês, então ficou mais fácil de nos relacionarmos. Eu já o conhecia de alguns eventos do meio artístico e mantivemos contato. Então, quando surgiu a ideia do projeto, vimos que era um interesse em comum."

Em relação às turnês de teatro, as networks também foram importantes:

"A partir do contato que tínhamos em Nova York e França, foi que surgiu a oportunidade de realizarmos a turnê nesses lugares. A gente que trabalha nesse meio, isso é importante. Ter contatos é muito importante."

$\mathrm{Na}$ área audiovisual, as produtoras buscam desenvolver relacionamentos com outras produtoras, artistas, instituições públicas, privadas que apoiam a arte e cultura e organizadores de eventos culturais, atuantes no seu país e no exterior para explorar novas oportunidades. No caso da Franco Produções e Filmes, a empresa atuava na produção e participação de mostras internacionais de cinema, o que possibilitou o empreendedor conhecer outras pessoas para o desenvolvimento de projetos culturais (OZGEN; BARON 2007).

Os benefícios alcançados pela Franco Produções e Filmes com as networks, ratificam os pressupostos de Ellis (2011), pois as redes ofereceram acesso a novas informações e conhecimentos sobre o novo mercado, maior acesso a recursos financeiros, acesso a novos recursos humanos e contato com potenciais clientes. 
Com relação à dimensão de conhecimento e aprendizado, o empreendedor já havia visitado os Estados Unidos, França e a Argentina e, em sua opinião, isso contribuiu para que ele pudesse realizar os projetos com mais facilidade nesses países. Dessa forma, quanto maior for o conhecimento e experiência internacional prévia do empreendedor, maiores as chances de identificar novas oportunidades internacionais (AUTIO, SAPIENZA, ALMEIDA, 2000).

Uma das citações de Ailton Franco sobre conhecimento:

"Todos esses mercados em que fizemos ou estamos fazendo projetos internacionais, eu já conhecia antes e acho que esse conhecimento me ajudou na internacionalização da empresa. Eu já conhecia algumas pessoas desses países, conhecia a cultura, como funcionava o país e isso ajuda."

Com esse conhecimento prévio, Ailton Franco ampliou a sua capacidade de compreender a realidade do novo mercado em que a empresa estava atuando - leis, cultura, governo, os atores locais e até possíveis parceiros (SHANE; VENKATARAMAN, 2000). Outra característica importante foi a capacidade de aprendizado.

"Eu tenho um conhecimento sobre o exterior muito grande, eu sempre fiz coisas no exterior, até como pessoa física mesmo. Fiz o curso na França, e quanto mais a

gente trabalha lá fora, mais a gente aprende e vai ganhando novos conhecimentos. "

Por outro lado, com relação aos conhecimentos sobre o processo de internacionalização de negócios, Ailton Franco disse que não possuía muitas informações, mas que foi aprendendo na prática, perguntando para os amigos e pesquisando na internet.

No que se refere a possíveis formas de obtenção de conhecimento - network, aquisição, imitação e pesquisa - segundo os estudos de Saarenketo et al. (2004), verifica-se que no caso da Franco Produções e Filmes, o conhecimento foi obtido através das network, aquisição (com a contratação de funcionários temporários) e pesquisas sobre informações sobre os novos mercados e operação.

Abordando os aspectos do perfil empreendedor, que facilitam a exploração de oportunidades internacionais, Ailton Franco afirmou que na Franco Produções e Filmes, tanto ele como os funcionários são estimulados a utilizar a criatividade no seu dia-a-dia, além de demonstrar coragem, iniciativa e persistência (WELPE et al, 2012). Ailton Franco comenta:

"A criatividade e a coragem ajudam a gente a pensar fora da caixa, improvisar e resolver qualquer problema que aparece. Isso tudo é importante quando vai trabalhar lá fora. Isso ajuda a criar novos projetos para o exterior."

Ao mesmo tempo em que podem estimular a identificação e exploração de oportunidades, podem ser também um fator limitador nesse processo (DE BONO, 1989). Ailton Franco também enfrentou obstáculos para explorar as oportunidades internacionais que se apresentaram. Entre os principais empecilhos, podemos citar questões do ambiente cultural e ambiente político.

Com relação à questão cultural, uma das dificuldades foi com relação ao idioma, fator que afeta diretamente a estrutura do projeto cultural. Ailton Franco comenta:

"Nos espetáculos teatrais, os textos são feitos em português aí você precisa fazer a legendagem eletrônica para o público acompanhar. E o texto, obvio, tem que sofrer certas adaptações, não dá pra fazer uma tradução literal. Principalmente no caso de expressões idiomáticas." 
Ainda sobre a questão cultural, houve a dificuldade quanto ao entendimento de hábitos e costumes de culturas diferentes. Em um episódio ocorrido na França, a diferença de tratamento causou um desentendimento entre a equipe de Ailton Franco e a empresa francesa.

"Lá na França, tivemos um desentendimento, os nossos parceiros de lá, não queriam buscar a nossa equipe no aeroporto, depois de 11 horas de viagem, ainda iríamos trabalhar no dia seguinte. Pode ser que eles não tenham esse habito de buscar no aeroporto, mas aqui no Brasil, não é assim, eu nunca faria isso com eles. Os dois lados precisam se entender e entender a cultura do outro."

Na questão política, Ailton Franco destaca que se deve sempre prestar atenção às regras do país, entender as leis e se necessário se adaptar a essas novas situações. Um dos exemplos citados pelo empreendedor foi:

"Nos Estados Unidos tem uma lei que dizia que era totalmente proibido ter fogo dentro de espaço fechado e no nosso espetáculo tinha vela, pessoas que fumavam e tivemos que adaptar, botamos cigarro eletrônico e velas eletrônicas. E o cigarro eletrônico a gente não podia nem acender."

Outra dificuldade expressada por Ailton Franco se refere à limitação do conhecimento sobre o local da produção. Não só quando uma empresa brasileira vai fazer alguma produção no exterior, mas também quando alguma produtora estrangeira vem para o Brasil. $\mathrm{Na}$ coprodução realizada com os parceiros franceses, Ailton Franco relata a necessidade de adaptar o texto original, pois o autor não conhecia aspectos geográficos, operacionais e de transportes no Rio de Janeiro, como por exemplo, a distância entre bairros e tipos de voos que os aeroportos Santos Dumont e Galeão oferecem.

\section{Considerações Finais}

O presente estudo possibilitou uma análise dos tipos de oportunidades identificadas e das variáveis envolvidas no processo de exploração de oportunidades internacionais de uma empresa brasileira atuante no setor de audiovisual. Além disso, a pesquisa também permitiu identificar tipos diferentes de oportunidades, como as arbitrárias e inovadoras, bem como evidenciar as oportunidades descobertas e as oportunidades que foram criadas pela empresa.

A habilidade do empreendedor em desenvolver networks foi de grande importância e influência no processo de entrada nos mercados internacionais. O estabelecimento de parcerias e projetos de coprodução estabelecidos a partir das suas redes de relacionamento social e eventos no Brasil e no Exterior foram decisivos para a Franco Produções e Filmes internacionalizar sua operação. Na perspectiva do conhecimento e aprendizado, Ailton Franco demonstrou a sua capacidade de traduzir informações, experiências e diferenças em culturais em ações efetivas na produção de espetáculo e filme num contexto diferente de seus pais de origem, respeitando e se adequando a fatores culturais e políticos.

Outras características importantes no processo de exploração de oportunidades internacionais da Franco Produções e Filmes foram a criatividade (perfil do empreendedor) e a flexibilidade na gestão de recursos. Essas características ajudaram a alavancar a capacidade da empresa e do empreendedor no desenvolver e testar novas possibilidades de atuação e resolver contingências.

Conclui-se que foi possível identificar, no caso da Franco Produções e Filmes, as variáveis do processo de exploração de oportunidades - flexibilidade de recursos, networks, perfil empreendedor, conhecimento e aprendizado, pressões do ambiente. Isto permitiu à

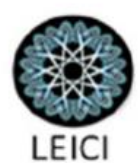


empresa não somente identificar e explorar oportunidades no exterior, como também maximizar a criação e a entrega de valor superior para seus clientes nos mercados nacional e internacional.

O presente estudo teve um caráter exploratório e suas contribuições não esgotam o tema pesquisado. Como sugestão para estudos futuros, propõe-se, inicialmente, a replicação do estudo com uma quantidade maior de casos, possibilitando resultados mais amplos para que as diferenças entre os grupos possam ser identificadas. Sugere-se, também, avaliar o modelo no contexto de outros setores da indústria criativa.

\section{Referências}

ÅKERMAN, N. International opportunity realization in firm internationalization: Non-linear effects of market-specific knowledge and internationalization knowledge. Journal of International Entrepreneurship, v. 13, n. 3, p. 242-259, 2015.

ALDRICH, H.E.; KENWORTHY, A. The accidental entrepreneur: Campbellian antinomies and organizational foundings. Variations in organization science: In honor of Donald T. Campbell, p. 19-33, 1999.

ALVAREZ, S.A.; BARNEY, J.B. Discovery and Creation: Alternative theories of entrepreneurial action. Strategic Entrepreneurship Journal. Vol 1, p. 11-26. 2007.

ANOKHIN, S.; WINCENT, J.; AUTIO, E. Operationalizing opportunities in entrepreneurship research: use of data envelopment analysis. Small Business Economics, v. 37, n. 1, p. 39-57, 2011

ARDICHVILI, A.; CARDOZO, R.; RAY, S. A theory of entrepreeurial opportunity identification and development. Journal of Business Venturing 18 p. 105 -123. 2003.

AUTIO, E.; SAPIENZA, H.J.; ALMEIDA, J.G. Effects of age at entry, knowledge intensity, and imitability on international growth. Academy of management journal, v. 43, n. 5, p. 909 924, 2000.

BARDIN, I. Análise de conteúdo. Lisboa: Edições Setenta, 1994. 226 p.

BENDASSOLLI, P.F. Análise do mercado de trabalho e carreira nas indústrias criativas do estado de São Paulo. 2008.

BLYTHE, M. The work of art in the age of digital reproduction: the significance of the creative industries. International Journal of Art \& Design Education, v. 20, n. 2, p. 144-150, 2001. CASULLI, L. Exploring opportunity creation in internationalizing SMEs: Evidence from Scottish firms. Internationalisation, entrepreneurship and the smaller firm: Evidence from around the world, p. 20-36, 2009.

CHANDRA, Y.; STYLES, C.; WILKINSON, I. The recognition of first time international entrepreneurial opportunities: Evidence from firms in knowledge-based industries.

International Marketing Review, v. 26, n. 1, p. 30-61, 2009.

CORBETT, A.C. Learning asymmetries and the discovery of entrepreneurial opportunities. Journal of business venturing, v. 22, n. 1, p. 97-118, 2007.

DA SILVA, A. L.; DE ALMEIDA CUNHA, C. J. C. Busca de oportunidades: o caminho da competitividade. Gestão \& Produção, v. 1, n. 1, p. 89-97, 1994.

DALLA COSTA, A.; DE SOUZA-SANTOS, E.R. Economia criativa: novas oportunidades baseadas no capital intelectual. Revista Economia \& Tecnologia, v. 7, n. 2, 2011.
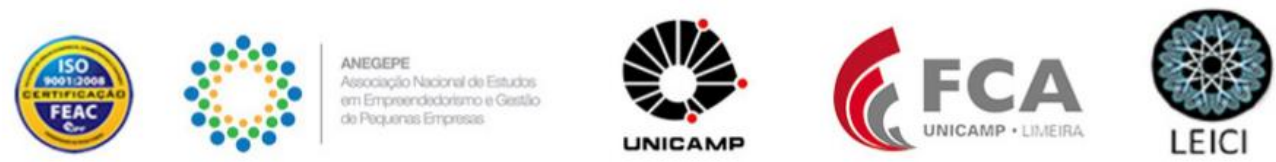
DE BONO, E. Oportunidades: um manual para a busca de melhores oportunidades nos negócios. Vértice, São Paulo, 1989.

DELLAGNELO, EHL; SILVA, R. C. Pesquisa Qualitativa em Administração: teoria e prática. Rio de Janeiro: FGV, 2005.

DRUCKER, P.F. Management: Tasks, responsibilities, practices. truman talley Books, 1986.

ECKHARDT, J.T.; SHANE, S.A. Opportunities and entrepreneurship. Journal of management, v. 29, n. 3, p. 333-349, 2003.

FAROQUE, A.R. Network exploration and exploitation in international entrepreneurship: an opportunity-based view. 2014.

FIRJAN. Mapeamento da indústria criativa no Brasil. Rio de Janeiro: Sistema Firjan (Federação das Indústrias do Estado do Rio de Janeiro), dez. 2016.

FLORIDA, R. Cities and the Creative Class. Carnegie Mellon University: City \& Community Vol. 2, n. 1, 2003.

ELLIS, P.D. Social ties and internacional enterpreneurship: Opportunities and constraints affecting firm internationalization. Journal of Internacional Business Studies. Basingstoke, Hampshire: Palgrave Macmillan, - Vol. 42, n.1, p. 99-128, January 2011

FERREIRA, M.P.; REIS, N.; SERRA, F.R. Marketing para empreendedores e Pequenas Empresas. São Paulo, Atlas 2010.

INOVA.JOR. Economia criativa cresce acima da média mundial no Brasil. Disponível http://www.inova.jor.br/2017/08/24/economia-criativa-brasil/ Acesso em: 10 de fev.2018.

JUDGE, W.Q.; BLOCKER, C.P. Organizational capacity for change and strategic ambidexterity: Flying the plane while rewiring it. European Journal of Marketing, v. 42, n. 9/10, p. 915-926, 2008.

KIRZNER, I. Competition and Entrepreneurship. University of Chigago Press. 1973

KIRZNER, I. Perceptions, Opportunities, and Profit. University of Chicago Press. Chicago. 1979.

KONTINEN, T.; OJALA, A. Network ties in the international opportunity recognition of family SMEs. International Business Review, v. 20, n. 4, p. 440-453, 2011.

LEVINTHAL, D.A. Adaptation on rugged landscapes. Management science, v. 43, n. 7, p. 934-950, 1997.

MAINELA, T.; PUHAKKA, V.; SERVAIS, P. The concept of international opportunity in international entrepreneurship: a review and a research agenda. International Journal of Management Reviews, v. 16, n. 1, p. 105-129, 2014.

MCMULLEN, J. S.; SHEPHERD, D.A. Entrepreneurial action and the role of uncertainty in the theory of the entrepreneur. Academy of Management review, v. 31, n. 1, p. 132-152, 2006. MILLER, K. D. Risk and Rationality in entrepreneurial processes. Strategic Entrepreneurship Journal. Vol 1, p. 57-74. 2007.

OLIVEIRA, J.M.; ARAUJO, B.C.; SILVA, L.V. Panorama da economia criativa no Brasil. 2013.

OLIVEIRA, D.P.R. Planejamento Estratégico: conceitos, metodologias e práticas. 4aed. sac) Paulo: Atlas, 1989.

OVIATT, B. M.; MCDOUGALL, P.P. Defining international entrepreneurship and modeling 
the speed of internationalization. Entrepreneurship Theory \& Practice, v. 29, n. 5, p. $537-$ 553, 2005a.

OZGEN, E.; BARON, R.A. Social sources of information in opportunity recognition: Effects of mentors, industry networks, and professional forums. Journal of business venturing, v. 22, n. 2, p. 174-192, 2007

SAARENKETO, S. et al. Dynamic knowledge-related learning processes in internationalizing high-tech SMEs. International Journal of Production Economics, v. 89, n. 3, p. 363-378, 2004.

SCOTT, A. J. The cultural economy of cities. International journal of urban and regional research, v. 21, n. 2, p. 323-339, 1997.

SCHUMPETER, J.A. The schumpeter: Theory economic development. Harvard University Press, 1934.

SCHUMPETER, J.A. Creative destruction. Capitalism, socialism and democracy, v. 825, 1942.

SHANE, S.A. Prior knowledge and the discovery of entrepreneurial opportunities. Organization science, v. 11, n. 4, p. 448-469, 2000.

SHANE, S.A. A general theory of entrepreneurship: The individual-opportunity nexus. Edward Elgar Publishing, 2003

SHANE, S.; VENKATARAMAN, S. The promise of entrepreneurship as a field of research. Academy of management review, v. 25, n. 1, p. 217-226, 2000

SODERQVIST, A. Opportunity exploration and exploitation in international new ventures: A study of relationship's involvement in early internationalisation events. Hanken School of Economics. 2011.

STEVEN WHITE, D.; GUNASEKARAN, A.; H. ROY, M. Performance measures and metrics for the creative economy. Benchmarking: An International Journal, v. 21, n. 1, p. 46-61, 2014.

STEVENSON, H.H e JARILLO, J. C. Preserving entrepreneurship as companies grow. The Journal of Business Strategy, Vol. 6. p. 10-23. 1986

UNCTAD - UNITED NATIONS CONFERENCE ON TRADE AND DEVELOPMENT. Creative economy report 2010.Creative economy: a feasible development option. U.N., 2010.

WEICK, K.E. Cognitive processes in organizations. Research in organizational behavior, v. 1, n. 1, p. 41-74, 1979.

WELPE, I. M. et al. Emotions and opportunities: The interplay of opportunity evaluation, fear, joy, and anger as antecedent of entrepreneurial exploitation. Entrepreneurship theory and practice, v. 36, n. 1, p. 6996 (2012)

WYSZOMIRSKI, M.J. Defining and developing creative sector initiatives. Ohio state university, 2004.

ZAHRA, S.A. A theory of international new ventures: a decade of research. Journal of International Business Studies, v. 36, n. 1, p. 20-28, 2005.

YIN, R. K. Estudo de caso. Planejamento e métodos. Porto Alegre, 2005. 